\title{
Animal Pharmacology Shared Resource
}

National Cancer Institute

\section{Source}

National Cancer Institute. Animal Pharmacology Shared Resource. NCI Thesaurus. Code C39323.

Animal Pharmacology Shared Resource provides support and expertise to Cancer Center investigators in evaluation of the pharmacological effects of drug candidates in clinically relevant animal models. 